\title{
Research on Daily Costume of Women from China's Shui Nationality of Sandu in Guizhou Province
}

\author{
Chenqu Ma ${ }^{1}$, Xiangyang $\operatorname{Bian}^{1} \&$ Shiman $\mathrm{Li}^{2}$ \\ ${ }^{1}$ Fashion \& Art Design Institute, Donghua University, Shanghai, China \\ ${ }^{2}$ Fashion College, Zhejiang Textile and Costume Vocational Technical Institute, Hangzhou, China \\ Correspondence: Xiang Yang Bian, Fashion \& Art Design Institute, Donghua University, 1882 West Yan'an \\ Road, Changning District, Shanghai, China. Tel: 1-370-171-5417. E-mail: bianxiangying@163.com
}

Received: October 6, 2018

doi:10.5539/ass.v14n12p266
Accepted: November 7, $2018 \quad$ Online Published: November 29, 2018

URL: https://doi.org/10.5539/ass.v14n12p266

\begin{abstract}
Through a great number of fieldwork, this article did a detailed investigation and analysis on the current situation of women's daily ethnic costumes from the China's Shui nationality in Shui autonomous county of Sandu in Guizhou Province. Differed from the former researches on the classification of women's dress from Shui nationality, this article divided the existing women daily dress into three types according to the current situation. Influenced by the geography and surrounding culture, costume of Shui Minority has formed regional characteristics. According to the different location, this article divides the women's ethnic costumes, which are still used as daily wear, into three types: the Central style, the Eastern style and the Southern style. By comparative analysis among the 3 different dressing ways, the paper deeply analyzed the distinguishes of different types of women's daily ethnic costumes from Shui nationality, and discussed the reasons why differences exist.
\end{abstract}

Keywords: Shui Nationality, women, modernization, ethnic costumes

Shui Nationality is one of the 55 ethnic minorities in China, with more than half of the population living in the Sandu Shui Autonomous County in the southeastern part of Qiannan Buyi and Miao autonomous prefecture, Guizhou Province. Because of the small populations and the location is in remote area, there have been few studies on traditional clothing. Among the few research results on clothing and apparel, the research results of Maweixiu (An unique embroidery of Shui Nationality that use horsetail to be the core of the embroidery threads) are the majority, and there are few researches on clothing and apparel, only some short journals. Most of the research about clothing and apparel are a short part of the local history, or a small part of the study of minority costumes. These studies mainly focus on the simple description of clothing in different regions, and there is no specific research on their daily clothing.

Sandu is the place where Shui Minority had been living for all generations, together with Han, Miao, Dong and Buyi ethnics. With crash and fusion among different ethnic cultures, Shui's costumes had asorbed advantages and formed its own characteristics. Escaping from the huge trend of foreign fashion spreading all China, Sandu had remained its tradition, according to which women wear their minority costumes to go to crops market, shopping and work in the fields. Absolutely, the traditional costume routine has great value to inspire people's creativity, regional communitted union and extend excellent ethic cultures.

\section{Styles of Sandu Women's Daily Costume}

Due to geographical discrepancies and mixed residence, there are regional differences among Sandu women's costumes. We must admit that some districts did not wear ethnic costumes as daily dresses. So according to different areas, this paper divided Shui minority's costumes as 3 types as follows:

Central style: This style is mainly the costumes of the central part of Sandu County, such as Sandong, Zhonghe, Shuilong, Tangzhou, Tingpai, Hengfeng, Zhouyi, Hejiang, Dahe, Sanhe.

Eastern style: This style is mainly the clothing of the eastern part of Sandu County, such as the clothing of the town, such as Lalan, Dayu, Dujiang, Bajie, Wubu, and Yangfu.

Southern style: mainly clothing in the southern part of Sandu County, such as clothing in towns such as Jiuqian and Yanggong. 


\section{Analysis and Comparison of Shui Women's Daily Clothing Categories}

The main categories of daily clothing for Shui Nationality women are headscarves, coats, pants, aprons, shoes, bags, and silver ornaments. From the category, there are no essential differences, it is the combination of the tops and pants, but there are some differences in the details of different types of clothing, thus forming different styles of clothing. In the following, according to different types of clothing, this paper has analyzed the similarities and differences of different styles of clothing

\subsection{Headscarf}

The women of Shui treat headscarves as their main headwear in their daily lives. The three types of headscarves are different in the style and the way of tie the headscarf (see Table 1). In the condition of the modern transportation is increasingly developed, and communication is becoming more and more convenient, there has been a serious phenomenon of assimilation in different categories of clothes-- the coats, trousers and shoes of central-style have affected women's clothing in other regions. So only the regional features of the headscarf are visible. Therefore, the differences in headscarves are the most obvious feature distinguishing women's clothing among different types.

The way of tying the Central style headscarf is twirling. The headscarf is about $180 \mathrm{~cm}$ long and $35 \mathrm{~cm}$ wide, and the edges are loose and have no tassels. The color is mainly white, black and dark navy. The white color is mostly adapted by young women, and black is used by elder women. The way of tie the headscarf is as follows: before tying the headscarf, coil up the hair on the top of the head, and insert a long comb on the right side to fasten the hairshape and also serve as a decoration. Some people use a hairnet to fasten the hair, and then tie the headscarf. As the steps in Table 1, the first step is to cover the long towel at 1/3 and make one side long; in the second step, the two sides of the long scarf the two sides of the long scarf should be folded around a whole and a half of head. The short side is left behind the head, and the long end is wound halfway from the back to the front and placed in the forehead part; in the third step, the short side is rotated from below and turned upside down, and placed in the circle around the head.

The way of tie the Eastern-style headscarf is mainly wrapped. The headscarf is about $100 \mathrm{~cm}$ long and about $35 \mathrm{~cm}$ wide. There are 3 gray stripes of width about $1 \mathrm{~cm}$, leaving fringe about $5 \mathrm{~cm}$ at the edge, and tassels about $5 \mathrm{~cm}$ long, at the edge of two sides. The color is mainly white, but also gray, cyan, and darker for older women. The way of tying the headscarf is as follows: before tying the headscarf, hair up and insert a comb at the back of the head. The first step is to fold the long scarf in half, and the width can be wide; In the second step, the headscarf is divided into three sections, and the two sides are folded together in the middle; In the third step, the pin is passed through the inside five layers, leaving the outermost layer, then put the headscarf on the head.

The headscarf of Southern style is about $80 \mathrm{~cm}$ long and about $40 \mathrm{~cm}$ wide. There are long tassels on the edges. The texture is like the towel, but it is different from other types. The color is black, and the color is not distinguished with age and marriage. The way of tie the headscarf is as follows: before tying the headscarf, coiling up the hair on the top of the head. The first step is to fold the headscarf in half; the second step, align the center of the long headscarf with the forehead, and the two sides are folded inside a little, so that we can see from the front of the head is like a fan-shaped, and then it is placed on the top of the head and fixed with a clip; In the third step, the tassels of inner layer is pulled out from the top to make it hang down from both sides.

Table 1 . The types of headscarves

\begin{tabular}{|c|c|c|c|}
\hline Styles & Central style & Eastern style & Southern style \\
\hline \multicolumn{4}{|l|}{ Images } \\
\hline \multicolumn{4}{|c|}{ Ways of Tying } \\
\hline Length & About $180 \mathrm{~cm}$ & About $100 \mathrm{~cm}$ & About $80 \mathrm{~cm}$ \\
\hline Color & White, black & White & Black \\
\hline Feature & $\begin{array}{c}\text { The edges are loose and no } \\
\text { tassels. }\end{array}$ & $\begin{array}{l}\text { There are gray stripes and } \\
\text { tassels at the edge. }\end{array}$ & $\begin{array}{l}\text { The texture is like the towel, } \\
\text { long tassels at the edge. }\end{array}$ \\
\hline
\end{tabular}




\subsection{Coat}

The different types of traditional coats are basically similar, but there are still some differences in length, decorative patterns and other details.

\subsubsection{The Commonality of the Three Types of Coats}

All the coats have no collars and the closure is on the right side. If the decoration on the surface are removed, the pattern of these coats is traditional Chinese flat style-- the pieces are separated into left and right piece, not front and back piece, and there is no dart on all pieces. Limited by the width of the traditional local cotton fabric, the pattern of the sleeves piece is divided into two part like the traditional Chinese sleeves pattern. While the coat is made of modern woven fabrics, the sleeve and body piece are together (Figure 1). The sleeves are basically 8 to 9 points length, and the coats are connected by Pankou (the Chinese knot button).

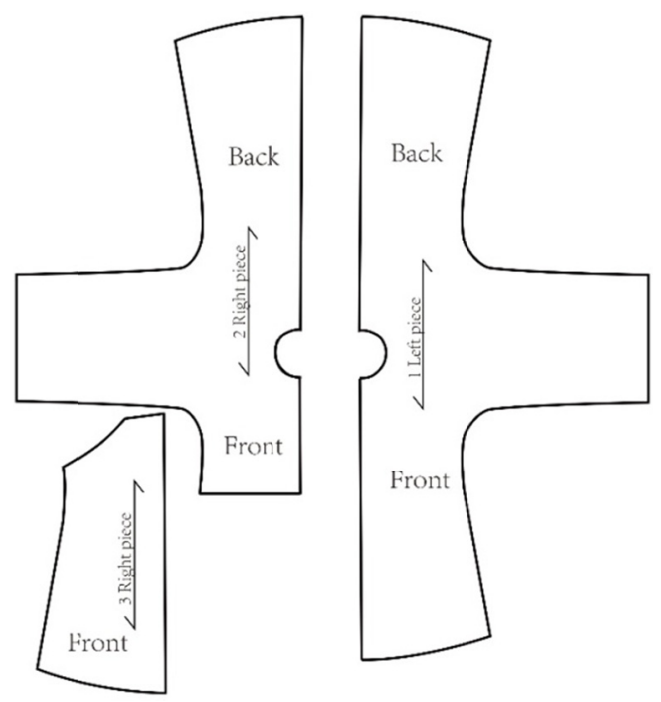

Figure 1. Coat's pattern

\subsubsection{The Difference Between the Three Types of Coats}

\section{Bodice differences}

Central style: The central style coats are divided into two types, A and B as shown in Table 2. The difference between them is the taping. All the edges of the A coat have tapings, and the B coat only has taping around the collar. The length of the central style coat is almost above the knee, but the old women's coat is longer, mostly under the knee.

Eastern style: The eastern style is basically the same with the central style B coat, there is no taping or decoration on the bottom of the bodice, only taping around the collar. The decoration of the bodice is more simple than central style coat. The length of the bodice is basically under the central thigh, and the length of the old women's coats are mostly above the knee.

Southern style: The southern style has no taping and decoration, the simplest compared to the other two styles. The length is similar to the central style, basically above the knee.

\section{Closure Differences}

Central style: the edge line of the closure is relatively curve, especially in the position of the chest, which is related to women's good at Maweixiu. In order to appropriate the thick fabrics of Maweixiu pieces, the pattern of the closure needs a smooth arc angle.

The closure of eastern-style and southern-style are relatively straight. There are only a few differences, such as the closure of eastern-style is end under the chest, while the closure of southern-style is end under the armpit as shown in Table 2.

\section{Pankou fastener differences}

Central style: the Pankou fastener's shape is very simple, and the color is commonly black. One Pankou fastener is horizontally put on the center of the neck, two vertically put on the right chest, and three on the right vent.

Eastern style: the Pankou fastener is butterfly-shaped as shown in Figure 2, and the color is commonly black. 
One Pankou fastener is horizontally put on the center of the neck, one vertically put on the right chest, and two on the right vent.

Southern style: the Pankou fastener's shape is very simple too, and the color is the same as the color of the bodice. One Pankou fastener is horizontally put on the center of the neck, two vertically put on the right chest, and two on the right vent.

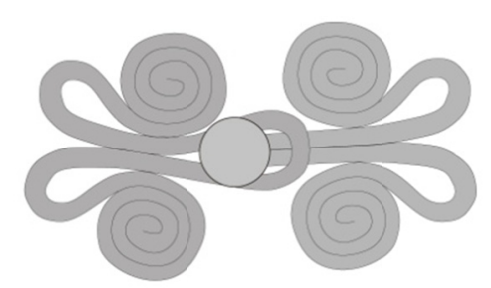

Figure 2. Eastern style's Pankou fastener pattern

\section{Sleeve differences}

Central style: The sleeves are relatively loose and attention to decoration. The cuffs are decorated with taping, piping and lace, and the taping is wide and the width is generally over $6 \mathrm{~cm}$.

Eastern style: The sleeves are narrow. And the cuffs are decorated with taping, piping and lace too, but the taping is narrow than Central style, the width is generally about $5 \mathrm{~cm}$.

Southern style: the sleeves are narrow and there is no decoration.

\section{Decoration differences}

The central style: the decorations are divided into three parts--the taping on the edge, the piping in middle and lace on the inside (Figure 3). The width of the taping is generally about $7 \mathrm{~cm}$, and depending on complexity of the decoration, there is also wider forms. The taping divides into two kinds - decorated or not. The decorations mainly use Maweixiu, the lace's embroidery follow the taping's. While the taping is decorated with Maweixiu, the lace is Maweixiu too. If the taping is not decorated, the lace is produced by machine. There are many kinds of machine lace, no pattern and color forming, which can be easily purchased from the market of village. There is also a piping between the taping and the lace. The original one has been a black fine piping with a width about $0.3 \mathrm{~cm}$. Now the styles of the garments have changed a lot, so some of the fine lace instead the piping. The cuffs are decorated in the same way as the bodice decoration, and the taping with Maweixiu is matched with the Maweixiu lace; the undecoration taping collocate the same lace on the bodice. In addition to the decoration of the taping, fine piping and lace, the coat which the taping is decorated is also decorated with a little piece on the vent of each side.

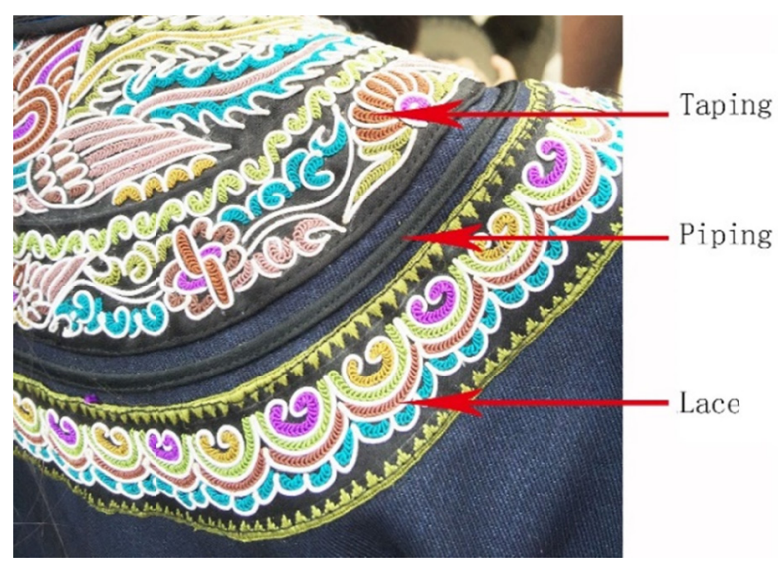

Figure 3. Decoration of the edge

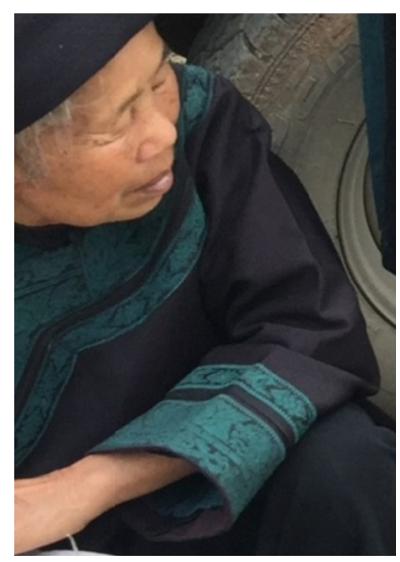

Figure 4. Green lace decoration of central style old women's coat

According to the most famous craftsman of Maweixiu-Mrs. Song Shuixian said, the women in the central region used to wear the coats, which are decorated by green silk laces (Figure 4). This traditional decoration way is now only reserved by a few elderly women. The kind of coats are decorated by one wide lace on the taping and one narrow lace inside, and are matched with blue or cyan fabrics. 
Eastern style: The decoration is divided into three parts, the taping on the edge of the garment, the fine piping and the lace. The taping is narrower than the central style, the width about $6 \mathrm{~cm}$ and the color is mainly black, without any decoration. The lace is narrower than the central style lace too, the width is about $2 \mathrm{~cm}$. The lace pattern is more unity, and the two sides are light and the middle is dark, which looks like two light-colored laces at a distance. There are some differences between the sleeves and the bodice in decoration. The lace of the sleeves is completely different from the lace on the bodice, while the width is narrower, about $1 \mathrm{~cm}$.

Southern style: There is no taping or decoration on the coat, the style is very simple.

\section{Differences in fabrics}

The coats of young women in central region is made of polyester fabrics, and the coat of elderly women is made of hand-craft cotton fabrics or machine-woven cotton fabrics. The coats of the eastern style are basically made of polyester fabrics, as do the elderly women. Although the women in Northern region are good at dyeing, but "Jiuqian" black fabric (a famous hand-made local black fabric) is very precious, so the coat of the northern style is also made of polyester fabrics.

\section{Differences in color}

The colors of elderly women's coats in central region are black, cyan and blue. And colors of young women's coats are cyan, blue and green. The colors of eastern-style women's coats are mainly blue and green, and some young women wear lighter blue and aqua green. The southern-style old women's coats are mostly black, and the young and middle-aged women's coats are mainly cyan, blue and green.

Table 2. The kinds of coats

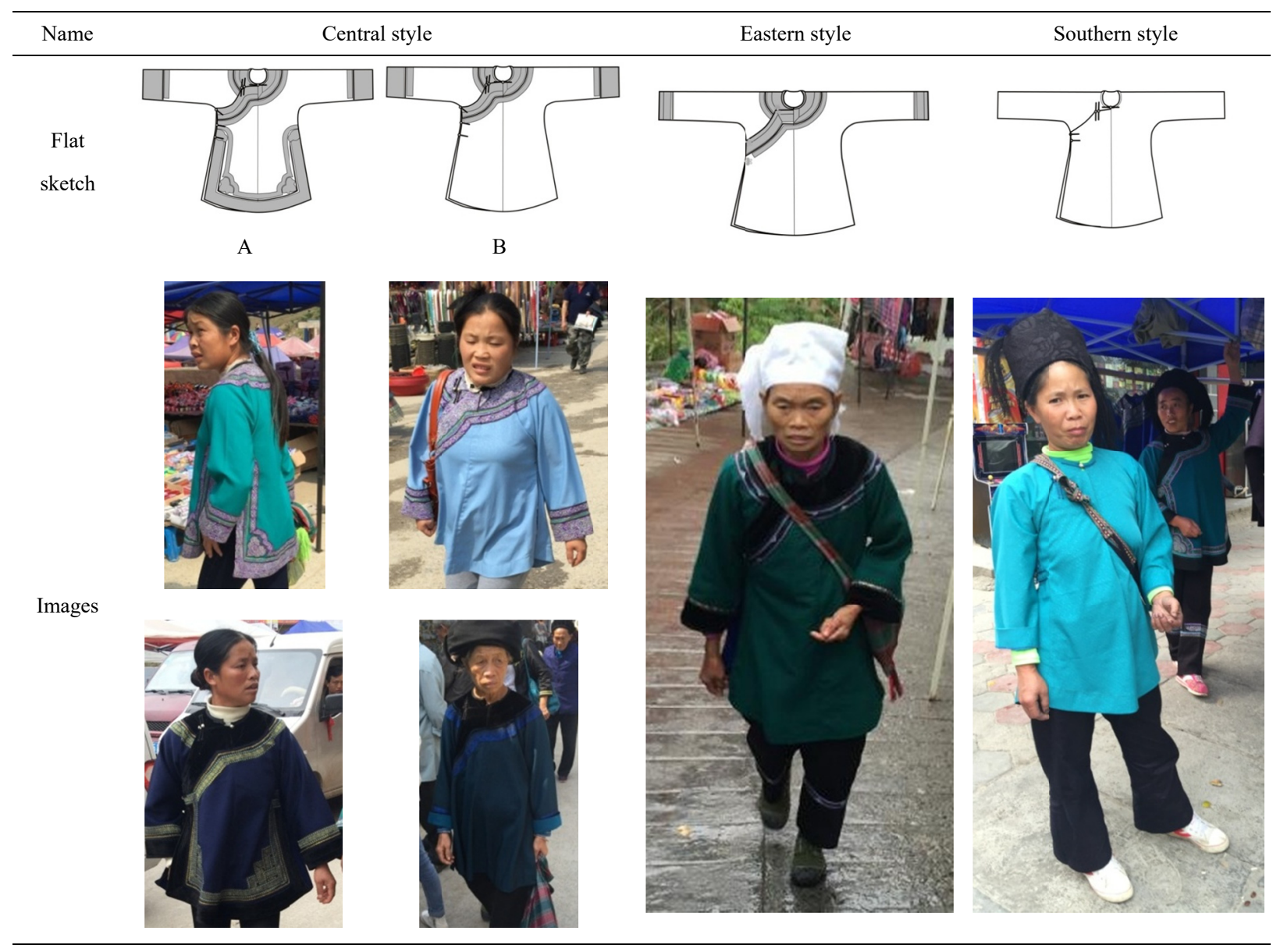

The assimilation and random wear of the coats has become more serious in recent years. For example, due to the convenience of transportation, frequent exchanges, the love of beauty, and the aesthetic appreciation of the women, the gorgeous central-style women's coat is favored by other regions' women. Such as in the Jiuqian village, the women often wear central-style coat, so it is difficult to distinguish their location with the coat, only can be recognized by their headscarf. At the same time, in the past several years, the clothing of Shui has become 
more and more colorful, and some pink, bright red and lemon-yellow colors have become popular among them. Due to the gradual decline of the national cultural connotation, it is no longer tabooed.

\subsection{Pants}

The women's costume bottom of Shui is mainly pants.

The central and southern styles' pants have no lace decoretion and are more fat. The fabrics and colors of the pants are not matched with the coats, the colors of the pants is darker than coats. The older women still have the habit of wearing traditional straight pants, but the young women rarely wear traditional pants, and jeans and slacks are young women's categories.

Eastern-style pants differ from the other two, and the trousers are decorated by lace at the calf position as shown in Table 2. Like other types, young women rarely wear traditional trousers, and only older women still have the habit of wearing traditional straight pants.

\subsection{Apron}

Due to daily routine needs, Shui's ethnic costumes are becoming simpler and simpler. We can hardly see women wearing apron during usual days. But in districts where aprons are still widely worn, there are regional discrepancies.

Central style: In the past, unmarried women wore long apron with embroidered breast pieces, while married women wore rectangular short aprons. But now this kind of custom is not taken seriously, so the apron is not a necessary item for daily clothing, and the married women also wear long aprons.

According to the length and the decoration, the aprons of central style is basically divided into the following three types: Undecorated short aprons, simple long aprons, and lace long aprons (Figure 5). The undecorated short aprons are worn by middle-aged and elderly women. It is only a black rectangle flannel or hand-made fabric, and tied with a geometric cross-stitch embroidery belt with the base fabric is black and the thread is green. The simple long aprons are a kind of aprons with an embroidered piece on the breast position. In addition to the embroidered pieces, there is only one lace decoration under the breast. The lace long aprons are the lace wrapped around the edge under the embroidered breast pieces. The two types of long aprons are mainly black, and are usually made of flannel or hand-made fabrics. It is worn with a silver chain on the neck and a white thick belt on the waist.

Eastern style: only one kind of no decoration, short and black aprons, only use a colored lace belt to tie the aprons (Figure 5).

Southern style: Women in this area basically do not need an apron in daily life.

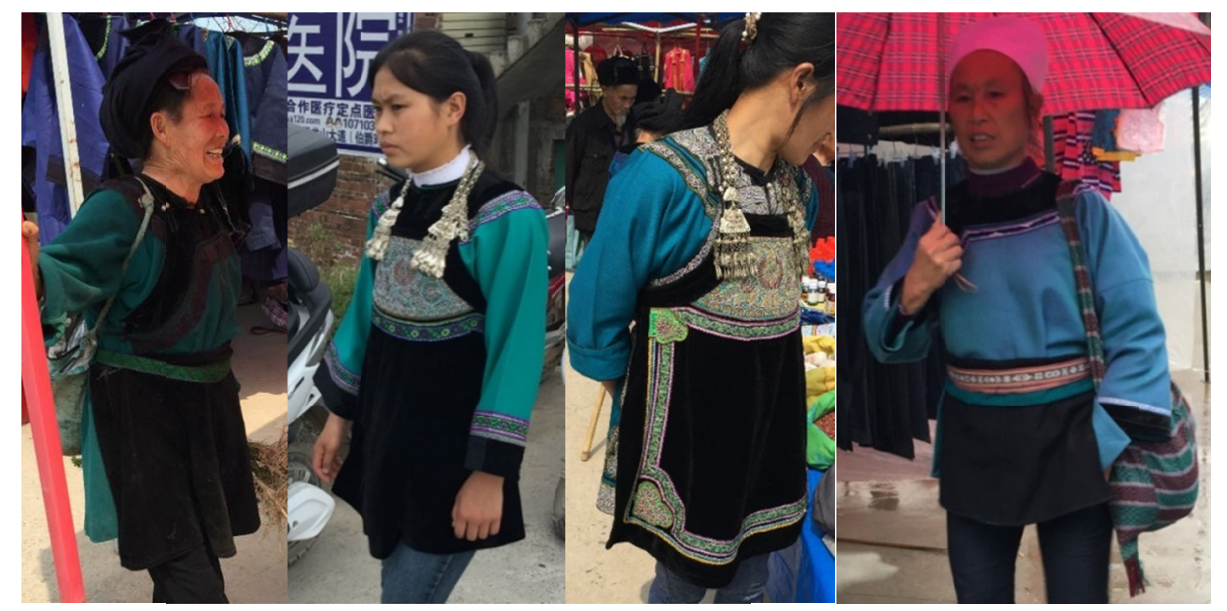

Figure 5. The kinds of Aprons

\subsection{Shoes}

Although women who wear traditional embroidered shoes are also seen, most young women still choose to wear modern shoes, while older women wear green China's Jiefang shoes (a kind of rubber-soled shoes). In addition to the traditional Maweixiu shoes, modern women like to wear embroidered round-toed shoes and new design high heels with Maweixiu (left in Figure 6). As an innovative product of traditional costumes, the high heels with Maweixiu is very popular in young women. 


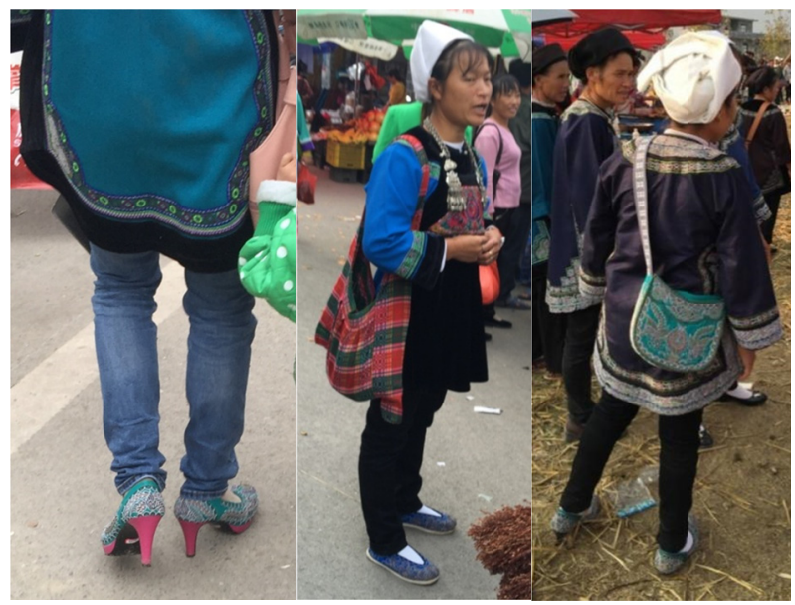

Figure 6. Featured shoes and bags

\subsection{Package}

Shui women's special crossbody bags (Figure 6) are widely worn in all areas of Sandu. This bag is sewn from one piece of yarn-dyed cotton fabric. The two sides of bottom are decorated with tassels, or the fabrics on both sides are extended to make two rectangular decorations. This bag is rich in color but very unity in style. In addition to this bag, the innovative Maweixiu bag (Figure 6) is also loved by young women now. Like the innovative high heels mentioned above, it is a new understanding of national costumes' fashion.

\subsection{Silver Ornaments}

There are fewer silver ornaments used in daily life, mainly silver combs, silver neck ring, silver bracelets and silver apron chains. The pattern is simple, and is matching with the women's daily wear. But the silver ornaments which are used on important occasions, are more elaborate and gorgeous, but it is not used for daily life, so it will not be discussed deeply in this article.

\section{The Reasons That Affect Women's Forming Differences}

Within the ethnic minority, the costumes of their branches are often similar in styles, but they show their own characteristics in terms of length, headwear, apron, and decoration, so that they can distinguish each other. The differences are somewhat influenced by internal factors, and some are influenced by other nationalities living together.

\subsection{Internal Factors}

The internal factors affecting women's wear are due to geographical differences, and historical changes.

First of all, the factors influencing the difference in their costumes are the different regions in which different types of clothing are located. In the past, under the condition of the arduous landform and underdeveloped transportation, there was less communication between different regions, so women in different regions formed their own characteristics.

Second, the historical changes have had some impact. In the Shu iareas, the policy of making Miao as a formal branch of Chinese nation, cutting their hair as Man Minority from Qing Dynasty, Changing their clothes into Han costumes, and living as the same ways as Han Nation. (Pan, 1981) was implemented during the Tongzhi Period of late Qing Dynasty, changed the women's clothes, the form of the Han Nationality women's costume - coat + pant replaced the original costume - coat + skirt. On this basis, the prototype of modern costume of Shui Nationality has been formed. Afterwards, the women of Jiuqian and Libo changed their costumes based on this situation. It is said that during the Xianfeng Period of late Qing Dynasty, the hero Pan Xinjian was very sympathetic to people who could not fill their stomachs and could not afford to buy lace and silk thread. He thought that he had to change the dynasty from the clothes at first. He and Wu Bangji and other revolutionaries discussed and decided to change women's wear and replace the previous decorative combination of long and short coats with a black gown. The women hair up changed the inverse form from left to right, replacing the black and white headscarf with a black headscarf. His proposal received the response of women. In just over one month, the women in Jiuqiao and Libo County were replaced with new wear. At that time, it was agreed that the original wear would be restored as soon as the uprising was won, but the uprising failed. In order to miss their leaders, the women abide by the promises until now $(\mathrm{He}, 1992)$. 


\subsection{External Factors}

The people of Shui live on the same area as the surrounding Han, Miao, Dong, and Buyi, they interact with each other, thus forming the different types of clothing. For example, women's wear in eastern area were affected by the wear of the neighboring people of Dong, forming a similar way of tie the headscarf, thus forming the eastern style.

\section{Conclusion}

In summary, although women's wear of Shui is roughly similar in category and styles, there are still differences in details, let them can be recognized by each other. The formation of these differences has influence within one nation to another. With the continuous development of time, because of the influence of more factors, the costume of Shui will continue develop and change. At present, some innovative national costumes have begun to replace the past costumes. Moreover, national costumes are gradually being replaced by modern apparels. Actually, the types of women's costume are not only three types, but have been replaced by modern apparels and disappeared in their daily lives. And a large number of young women no longer tie headscarves and no longer wear traditional pants and shoes. Therefore, by investigating and observing the current situation of Shui's ethnic costumes, it not only records the traditional costumes that are gradually disappearing, but also provides reference for the continuation of traditional costumes.

\section{Acknowledgments}

The authors would like to thank Donghua University, thanks for the editor and the readers of Asian Social Science.

\section{References}

He, J. (1992). Aquarium Folklore Exploration. Chengdu: Sichuan Nationalities Press.

Pan, Y. (1981). Shui's Social History. Guizhou: National Literature and History Research Group of Sandu Shui Minority Autonomous County.

\section{Copyrights}

Copyright for this article is retained by the author(s), with first publication rights granted to the journal.

This is an open-access article distributed under the terms and conditions of the Creative Commons Attribution license (http://creativecommons.org/licenses/by/4.0/). 